\title{
A construção estilística do cavaquinho e os processos de transmissão musical no choro: \\ a relação Galdino-Álvares-Canhoto
}

JAMERSON FARIAS RIBEIRO*

\begin{abstract}
RESUMO: Este artigo traz um recorte da minha dissertação (RIBEIRO, 2014) que propôs o estudo da práxis de um dos mais destacados nomes do cavaquinho brasileiro, Canhoto do Cavaquinho. Para caracterização de seu estilo foi realizada a análise e descrição de aspectos importantes de sua execução rítmica, tendo como base as gravações realizadas ao longo da carreira e a interação com o contexto sociocultural no período de seu aprendizado musical e profissionalização. Neste recorte abordaremos a relação entre sua construção estilística e a prática de cavaquinistas pioneiros do choro, observada a partir do conceito de ordem sonora, do etnomusicólogo John Blacking, além do processo de transformação de um estilo individual em referência para um gênero popular.
\end{abstract}

PALAVRAS-CHAVE: Cavaquinho brasileiro; Choro; Transmissão musical.

\section{The stylistic construction of the cavaquinho and the processes of musical transmission in the choro: the relation Galdino- Álvares-Canhoto}

\begin{abstract}
This article is an excerpt of my dissertation (RIBEIRO, 2014), which purposed to study the praxis of one of the most outstanding names of the Brazilian cavaquinho, Canhoto do Cavaquinho. In order to characterize his style it has been made an analysis of the recordings throughout his career and also of his interaction with the sociocultural context in the period of his musical learning and professionalization. In this paper I discuss the relationship between his stylistic construction and the pioneering practice of the cavaquinho in choro, observed from the concept of sonic order by the ethnomusicologist John Blacking, as well as the process of transforming an individual style into a reference of a popular genre.
\end{abstract}

KEYWORDS: Cavaquinho; Choro; Musical transmission.

\footnotetext{
* Jamerson Farias Ribeiro é cavaquinista, professor e pesquisador. É doutorando em Etnomusicologia pela Universidade Federal do Rio de Janeiro e graduado em Educação Musical na Universidade Federal do Ceará. Desenvolve pesquisa sobre o trabalho com música dos cavaquinistas. E-mail: jamersonfarias2@gmail.com

RIBEIRO, J. F. A construção estilística do cavaquinho e os processos de transmissão musical no choro: a relação Galdino-Álvares-Canhoto. Música Popular em Revista, Campinas, ano 6, v. 1, p. 31-55, jan.-jul. 
W aldiro Frederico Tramontano, o Canhoto do Cavaquinho (1908-1987), é considerado por músicos e pesquisadores como um dos principais representantes do cavaco-centro ou de acompanhamento na música popular brasileira. Consagrou seu estilo ao longo de quarenta anos de carreira, atuando em grupos como o Gente do Morro, o Regional de Benedito Lacerda e o Regional do Canhoto ${ }^{1}$, que tiveram fundamental importância na consolidação de um modelo básico de acompanhamento na música popular através do trio Dino-MeiraCanhoto $^{2}$, aliando violões em contraponto e cavaquinho centrista à percussão.

A temática relacionada ao estilo desenvolvido por músicos populares ligados ao choro vem sendo gradativamente trabalhada nos últimos anos dentro da academia ${ }^{3}$. Destacamos que os estudos analíticos dos instrumentos melódicos ligados ao choro (flauta, bandolim, dentre outros) possuem a partitura como ferramenta no processo de pesquisa - seja como fonte de material melódico ou como ferramenta no aprendizado musical - diferente dos instrumentos ligados ao acompanhamento (violão e, principalmente, cavaquinho), onde a transmissão musical é pautada no processo oral e aural. O fato é que, em ambos os casos, estudos desse tipo dependem essencialmente da análise de fontes primárias: as gravações comerciais, que se tornaram importantes registros das performances dos músicos. Para Carla Bromberg o conceito de "estilo" não tem consenso acadêmico, podendo significar uma linguagem musical, se referir a determinado período histórico, e ainda, a um estilo de compor (BROMBERG, 2011, p.430). Frequente, também, é a utilização do termo com

\footnotetext{
${ }^{1}$ Liderado pelo flautista Benedito Lacerda (1903-1958) o Gente do Morro surgiu em 1930 e seu nome fazia alusão à origem de alguns integrantes moradores do bairro do Estácio, no Rio de Janeiro. Em 1934 o grupo sofre modificações em sua formação passando a se chamar Regional de Benedito Lacerda, tendo as entradas de Dino e Meira em 1937. Uma parceria proposta por Benedito leva Pixinguinha (1897-1973) a integrar o grupo como saxofonista entre 1946 e 1950 - período em que gravaram cerca de 34 fonogramas e foram sucesso no programa "O Pessoal da Velha Guarda" dirigido por Almirante (Henrique Foréis Domingues, 1908-1980). Uma ruptura com Benedito levou a criação do Regional do Canhoto em 1951, que teve a saída de Pixinguinha e as entradas do flautista Altamiro Carrilho (1924-2012) e Orlando Silveira (1922-1993).

${ }^{2}$ Horondino José da Silva, o Dino Sete Cordas (1918-2006), violonista carioca, compositor e arranjador. Sua atuação ajudou a definir um modelo de execução para o violão de sete cordas, adotado por muitos instrumentistas posteriores a ele. Jayme Thomás Florence, o Meira (1909-1982), violonista pernambucano, professor de violão de instrumentistas como Raphael Rabello, Baden Powell e Maurício Carrilho.

${ }^{3}$ Ver Cândido e Sarmento (2005), Côrtes (2006), Taborda (1995), Becker (1996), Pellegrini (2005) e Bittar (2011).

RIBEIRO, J. F. A construção estilística do cavaquinho e os processos de transmissão musical no choro: a relação Galdino-Álvares-Canhoto. Música Popular em Revista, Campinas, ano 6, v. 1, p. 31-55, jan.-jul. 
o intuito de fazer referência a um modo particular de tocar um instrumento, um estilo individual.

Nesse sentido, a dissertação (RIBEIRO, 2014) se propôs a estudar a práxis do músico, caracterizando seu estilo por meio da análise e descrição de aspectos importantes de sua execução rítmica, tendo como base as gravações realizadas ao longo da carreira e a interação com o contexto sociocultural no período de seu aprendizado musical e profissionalização. No contexto do choro, o cavaco-centro tem a função de embasar a sonoridade do conjunto regional ${ }^{4}$ e dar sentido às intervenções e variações rítmicas e melódicas dentro formação. Nesta posição, a execução do cavaquinho é baseada nas palhetadas ou "levadas": construções rítmicas baseadas em células características de diversos gêneros e sua sonoridade é resultado de combinações entre articulações das mãos direita e esquerda ${ }^{5}$.

Identificamos que o estilo de palhetada de Canhoto mesclava elementos rítmicos ligados a padrões de acompanhamento do samba anteriores e posteriores às transformações sofridas na década de 1930 (SANDRONI, 2001), devido ao contato com a prática de músicos nascidos no século XIX, assim como outros oriundos do Estácio de Sá - bairro do Rio de Janeiro onde surgiram as inovações rítmicas. Sua profissionalização, no início da década de 1930, foi encarada no estudo como um ponto de partida para o processo de consolidação de seu estilo individual que alcançará maturidade nos anos 1950, com a criação do Regional do Canhoto. Mas como se constrói um estilo no contexto do choro? Que fatores levam uma "escola", um estilo individual a perdurar por diversas gerações como referência de prática?

A seguir discorreremos sobre os cavaquinistas antecessores de Canhoto e os processos de transmissão musical em seu período de aprendizado, sobre a possibilidade de seu estilo ter sido influenciado pelas transformações rítmicas ocorridas no samba, além de observar alguns fatores que contribuíram para transformação e manutenção do seu estilo em referência para gerações posteriores.

\footnotetext{
4 Formação instrumental de cavaquinho, violões, pandeiro e um solista (flauta, clarinete, bandolim, outros) que se consolidou no rádio na década de 1930.

5 Sobre escrita rítmica para cavaquinho ver Ribeiro (2017).

RIBEIRO, J. F. A construção estilística do cavaquinho e os processos de transmissão musical no choro: a relação Galdino-Álvares-Canhoto. Música Popular em Revista, Campinas, ano 6, v. 1, p. 31-55, jan.-jul. 


\section{A relação Galdino-Álvares-Canhoto}

A intepretação musical é um dos aspectos mais importantes do Choro e tornou-se um elemento marcante ao longo da trajetória histórica do gênero. Nesse contexto, músicos e ouvintes são capazes de opinar sobre diferentes aspectos de apresentação musical e, mesmo opondo-se em alguns, acabam concordando quanto à performance dos músicos. Em análise ao contexto da roda de choro, Lara Filho et al. observam que essa capacidade permite presumir a existência de uma "ordem que organiza o Choro como sistema musical, e que tal ordem é reconhecida pelos chorões, músicos ou audiência" (2011, p.148). O referencial do autor também reforça a importância de os estudos etnográficos sobre performance revelarem de que modo elementos não-musicais influenciam os musicais em determinadas ocasiões, além de evidenciar a inseparabilidade de música e contexto nesse tipo de pesquisa. A análise dos parâmetros musicais pode ser facilitada quando abordadas a partir do conhecimento produzido no próprio ambiente musical que não é composto exclusivamente pela música, mas por vários outros elementos (LARA FILHO et al., 2011).

O conceito de ordem sonora (sonic order), apresentado por John Blacking em How musical is man? (1973), pode ser entendido como um conjunto de significados e características, musicais ou não, relacionados a maneira como se deve organizar os sons (da criação à performance) compartilhados dentro de um sistema musical. Em práticas musicais que não são totalmente fundamentadas no "registro escrito convencional" (partitura), esses elementos são resguardados pela escuta crítica e pela performance e são compartilhados a partir de interações sociais imprescindíveis para a manutenção e recriação da tradição musical. Nesse sentido a escuta crítica pode ser definida como uma habilidade musical tanto quanto a execução de um instrumento, sendo totalmente possível aprender música, ou sobre ela, apenas participando de uma coletividade organizada por uma ordem, que pode ser expressa na música e em outros aspectos.

No caso do choro, a ordem pode estar relacionada a comportamentos e práticas sociais comuns ao gênero, assim como a segmentos mais específicos, 
relacionados a linguagens características dos instrumentos da formação básica do conjunto regional. No caso de Canhoto, observamos que seu aprendizado musical foi marcado pela interação com outros cavaquinistas em rodas de choro e aulas particulares, ambientes que deram ao músico conhecimento sobre a dita ordem sonora do choro, em especial do cavaquinho. Para Blacking (1973) é importante observar que os entendimentos e percepções individuais de uma determinada ordem sonora, são considerados fatores contribuintes para consolidação de estilos individuais e de novas perspectivas para uma manifestação musical. Esta ordem está em constante construção e, nesse processo, alguns músicos podem ter preponderância sobre outros.

Em entrevista ao autor a pesquisadora e cavaquinista Luciana Rabello identifica duas principais escolas de cavaco-centro na música brasileira, observando que apesar das dificuldades em defini-las com precisão, é possível perceber diferenças entre elas (RABELLO, 2014). Os acompanhamentos rítmicos característicos de cada escola teriam relação com os tipos de samba que existiam no Rio de Janeiro no final da década de 1920, assim como apresentado por Carlos Sandroni no livro Feitiço Decente (2001).

O tipo mais antigo é associado a Tia Ciata e aos compositores que frequentavam sua casa, como Donga, João da Baiana, Sinhô, Caninha, Pixinguinha. O tipo mais recente é associado a um bairro do Rio de Janeiro - chamado Estácio de Sá, ou simplesmente Estácio (em homenagem ao português que fundou a cidade em 1565) - e aos compositores que ali viviam ou circulavam: Ismael Silva (1905-1978), Nilton Bastos (1899-1931), Bide (Alcebíades Barcelos, 1902-1975), Brancura (Sílvio Fernandes, 19081935) e outros. (SANDRONI, 2001, p.131)

Valendo-se da nomenclatura de Sandroni, foram relacionados com a escola antiga os cavaquinistas pioneiros, oriundos do período entre final no século XIX e primeiras três décadas do século XX, ligados ao estilo mais maxixado de acompanhamento. Em contraste, a escola nova se caracteriza por acompanhamentos mais sincopados e tem como um de seus principais representantes o cavaquinista 
Jonas Pereira da Silva6. Dentre os cavaquinistas mais importantes da escola antiga podemos citar Mário Álvares, Galdino Barreto e Nelson Alves.

Segundo informações que foram retiradas de uma pequena biografia, produzida pelo violonista e copista Heitor Ribeiro ${ }^{7}$, encontrada no acervo pessoal de Canhoto8, Galdino Nunes Barreto ( 1860-1935) era cavaquinista e investigador aposentado da Ordem Política Social. O documento, que traz o único registo fotográfico de Galdino até momento, também nos revela que "dos discípulos de Galdino, o único sobrevivente é Waldir [sic] Tramontano, que com brilhantismo honra o mestre". Ao comentar sobre o acervo, Aragão (2011, p.224) sugere que o fato do documento com a foto de Galdino aparecer na primeira página de seu caderno/acervo demonstra admiração de Canhoto e, talvez, gratidão pelos os conhecimentos musicais transmitidos a ele.

Ao comentar sobre seu aprendizado em entrevista à Lilian Zaremba9, Canhoto afirma que teria pedido ao pai para contatar um professor de cavaquinho para ensina-lo, sem fazer menção ao nome de Galdino, o que geraria dúvidas sobre a relação direta professor-aluno. Porém, sabe-se que o pai de Waldiro costumava receber músicos em reuniões festivas que ocorriam em sua residência, conforme narrado na mesma entrevista, sendo este um ambiente de interação possível entre eles.

Objeto de pesquisa da tese do professor Pedro Aragão (2011), o livro O Choro - reminiscências dos chorões antigos foi escrito em 1936 pelo carteiro Alexandre

\footnotetext{
${ }^{6}$ Jonas Pereira da Silva (1934 - 1997) foi integrante do conjunto Época de Ouro, criado por Jacob do Bandolim. Seu estilo difere-se do de Canhoto pelo fato de a sonoridade de seus acompanhamentos serem mais seccionados ritmicamente (sincopados) podendo ser comparado a células rítmicas encontradas no tamborim.

${ }^{7} \mathrm{O}$ nome de Heitor Ribeiro aparece em algumas dedicatórias de partituras nos catálogos da Casa do Choro-RJ, além de ser identificado como copista de duas músicas: Com medo da Yara, de Juvenal Peixoto e Serenata, Ari de Corrêa de Sá.

${ }^{8}$ A IV edição do Festival Nacional do Choro, organizado pelo Instituto Casa do Choro e a Escola Portátil de Música (EPM) em 2008, homenageou o centenário de nascimento do músico. Em contato com seu filho, Adilson Tramontano, foi organizado um pequeno acervo, contendo fotos, recortes de jornais e revistas além de outros documentos referentes à carreira de seu pai. As imagens e documentos estão disponíveis para consulta no Centro de Pesquisa Jacob do Bandolim, na Casa do Choro-RJ.

9 Entrevista registrada em áudio por Lilian Zaremba para trabalho de conclusão de curso de graduação em história da PUC-RJ, em 1978. A transcrição da entrevista pode ser encontrada em Ribeiro (2014).

RIBEIRO, J. F. A construção estilística do cavaquinho e os processos de transmissão musical no choro: a relação Galdino-Álvares-Canhoto. Música Popular em Revista, Campinas, ano 6, v. 1, p. 31-55, jan.-jul. 
Gonçalves Pinto (apelidado de Animal) e é considerado um dos principais relatos para se entender o ambiente do choro no final do século XIX e início do século XX. O livro descreve músicos e ambientes musicais da época através de pequenos verbetes. Em um deles podemos perceber que Galdino era conhecido por ser um dos únicos professores de cavaquinho da época, reafirmando a relação Galdino-Canhoto.

\footnotetext{
Mestre dos mestres, que se celebrizou com o seu aprendiz Mário, cujo discípulo venceu naquela época todas dificuldades do instrumento transformando a sua tonalidade de quatro cordas para cinco, enquanto isso Galdino, continuava com o seu cavaquinho de quatro cordas tirando infinidades de tons e combinações de acordes que me é aqui difícil de descrever, tal é a magia, e a convicção das notas vibradas pela palheta encantada de Galdino, este grande artista, inigualável no meio dos chorões, aonde ele foi o único educador deste instrumento que se chama cavaquinho (GONÇALVES PINTO, 1936, p.70).
}

O trecho ainda se refere a superação sonora de um de seus discípulos, Mário Cavaquinho, evidenciando a condição de Galdino como professor do instrumento. Mário Álvares da Conceição ( 1861-1905) ficou conhecido por sua inovação ao inserir o cavaquinho de cinco cordas na música brasileira e fazer experiências com um instrumento de doze cordas (ou seis pares de corda) batizado por ele de Zebróide ou bando, uma espécie de bandurria - instrumento de origem espanhola, semelhante ao bandolim português (GONÇALVES PINTO, 1936; CÂNDIDO, 2019). Também era compositor e deixou cerca de quarenta e nove composições, dentre elas Roceira, Hilda (Teu beijo) e Segura a mão.

Analisando alguns outros verbetes do livro acreditamos na possibilidade de Álvares também ter ocupado a posição de mestre em relação a outros músicos como Lulu Cavaquinho e Biláu, corroborando a sugestão de Aragão (2011) que juntos, Galdino e Álvares, teriam construído um estilo, uma linguagem característica de tocar o cavaquinho que seria vinculada a eles.

Sobre Lulu Cavaquinho:

Bem poucos serão dos farristas de agora, que não conheceu o bom e excelente amigo Lulu' Cavaquinho. Era da turma de Mario, Galdino, Napoleão, Antenor de Oliveira, Quincas Laranjeiras, Juca Russo, Jorge Seixas, e muitos outros chorões, alguns ainda vivos. Era o grande executor acima de uma habilidade belíssima neste instrumento, pois não só solava, como também acompanhava muito bem. Lulu' vendo ser tocado e inventado por Mário, transformando o cavaquinho de quatro cordas, em doze, meteuse na cabeça, de também aprender, o que conseguiu com Mário, com grande 
facilidade. Este instrumento não havendo nomenclatura na música, Mário botou o nome de Bando, instrumento este, que supre o cavaquinho, e também sola em qualquer tom, sem precisar recorrer as oitavas. Hoje bem poucos o tocam, a não ser o grande musico Jorge Seixas aprendendo o mesmo sem mestre. Lulu' foi da turma dos bons, ainda hoje o seu nome é lembrado e comentado na roda dos chorões. (GONÇALVES PINTO, 1936, p.209)

E sobre Biláu:

Conheci bem criança, na Caixa Velha da Tijuca, onde seu sempre chorado pai ocupava alta posição. Retirando-me da Tijuca muitos anos. Depois precisando ir aquele bairro, encontrei Biláu já moço e atracado a um cavaquinho todo novo, e dos bons. Afinando o cavaquinho, fez ali um tom com todos seus acordes que fiquei bem admirado da sua agilidade naquele pequeno instrumento de arrebatar. Depois solou uma valsa se não me engano o nome é "Sorrir meu doce amor", esta valsa é bem custosa de solar, no entanto nos dedos de Biláu foi sopa. E ali dedilhou outra, de que me fez babar. Biláu foi aprendiz se não me engano do sempre chorado Mário do Cavaquinho, e que deu ao mestre grande gloria. Hoje acha-se retirado da luta, julgo com a morte do seu sempre chorado pai, e sua boa irmã. (GONÇALVES PINTO, 1936, p.111)

Ernesto dos Santos, o Donga ${ }^{10}$, que iniciou sua prática musical ao cavaquinho, atesta em depoimento ao Museu da Imagem e do Som do Rio do Janeiro (MIS-RJ) a importância do músico para o cavaquinho e para música brasileira, ao declarar que "todos nós que pegamos esse instrumento devemos tudo a essa escola do Mário, que foi um grande, um dos maiores compositores e solistas que já tivemos por aqui" (FERNANDES, 1970, p.75). Por meio das citações acima, ainda é possível observar que músicos com maior ligação a Mário Álvares parecem ter a prática como solista mais desenvolvida que a de acompanhador.

A relação entre Galdino, Álvares e Canhoto já havia sido observada por Aragão (2011) que, em estudo a práxis musical descrita por Gonçalves Pinto, destaca a presença dos chamados professores "informais", principalmente de violão e cavaquinho, no período da confecção do livro. A partir dos discursos dos primeiros memorialistas, Aragão constata a ligação entre três dos grandes nomes do cavaquinho: dois nascidos por volta da década de 1860 e um nascido na primeira década do século XX.

Temos assim a visão de pelo menos três referências da época - Pinto, Catulo e Vagalume - atestando que Galdino e seu discípulo Mário Álvares

\footnotetext{
${ }^{10}$ Ernesto Joaquim Maria dos Santos (1889-1974).

RIBEIRO, J. F. A construção estilística do cavaquinho e os processos de transmissão musical no choro: a relação Galdino-Álvares-Canhoto. Música Popular em Revista, Campinas, ano 6, v. 1, p. 31-55, jan.-jul. 
formaram uma espécie de "escola de cavaquinho" que seria passada para outras gerações. Embora não tenhamos como saber maiores detalhes sobre o método de ensino de Galdino, temos um forte indício de que sua "escola" teve reflexos até a segunda metade do século XX, influenciando um dos mais importantes cavaquinhistas do período que vai de 1930 até 1970 aproximadamente: Waldiro Tramontano, conhecido como Canhoto do Cavaquinho. (ARAGÃO, 2011, p.222)

O autor utiliza então o documento presente no acervo de Canhoto para comprovar que essa "escola" iniciada com Galdino tem forte ligação com Canhoto e sua prática que perdura até a década de 1970.

A ligação entre Galdino e Canhoto é encontrada em um documento
preservado em uma espécie de álbum que este último mantinha (e que hoje
se encontra em poder de sua família) com recortes de jornal da época com
"matérias" sobre o Regional do Canhoto. Na primeira página do álbum há
uma espécie de biografia de Galdino Barreto, laborada por um certo Heitor
Ribeiro, sobre quem não temos maiores informações. (ARAGÃO, 2011,
p.223).

Apesar de clara a formação de uma escola/linguagem por Álvares e Galdino, não se conhece, até o momento, gravações desses cavaquinistas que possam ser utilizadas em uma análise comparativa mais detalhada.

Dos três cavaquinistas pioneiros abordados nesta seção, o único que possui sua pratica registrada em disco é Nelson Alves (1895-1960), sendo estas as fontes de análise interpretativas para relacionar Canhoto e a escola antiga. O músico atuou em muitas gravações desde o início do século XX como solista11 e como acompanhador. Segundo o verbete dedicado a Alves no site de Pixinguinha, iniciou sua carreira na década de 1910 no Grupo Chiquinha Gonzaga (com o flautista Antônio Maria Passos) e no Grupo Carioca, com Candido Pereira da Silva, o Candinho do Trombone (1879-1960), como solista. A partir de 1919 passou a integrar o grupo Os Oito Batutas, participando das viagens do grupo à França e à Argentina (NELSON ALVES, 2019). É autor de peças clássicas do reportório de choro como Mistura e manda, Serpentina e Nem ela nem eu, algumas delas gravadas pelo Regional do Canhoto anos mais tarde.

Para caracterização da escola antiga, realizamos audições de músicas gravadas por Alves onde ele aparece como acompanhador (nos Os Oito Batutas, por

\footnotetext{
${ }^{11}$ Ficou calmo e Não pode ser (Victor - 33.205:1929); Nem ela nem eu (Brunswick -10.067:1930); Eu vi você e Não tem dúvida (Parlophon -13.084:1929).

RIBEIRO, J. F. A construção estilística do cavaquinho e os processos de transmissão musical no choro: a relação Galdino-Álvares-Canhoto. Música Popular em Revista, Campinas, ano 6, v. 1, p. 31-55, jan.-jul. 
exemplo). Nelas pudemos identificar uma das principais características do estilo dessa escola de cavaco-centro: a utilização de uma palhetada-base para o acompanhamento de diversos gêneros musicais, como veremos mais detalhadamente adiante. Em um período de consolidação da música popular indicações de gênero tinham como intuito transmitir aos interpretes o caráter sincopado da música brasileira. Bem verdade que, em algumas gravações, o centro rítmico-harmônico apresenta um som mais curto, com pouco sustain, dificultando a identificação dos instrumentos presentes no acompanhamento. A sonoridade se justificaria pela grande utilização do banjo por parte dos músicos do período (de acordo com a iconografia disponível) e por questões tecnológicas, como o tipo de corda que era utilizado pelo instrumento. No entanto, não conseguimos maiores informações sobre o assunto.

Frente ao exposto acima, observa-se a importância do contexto sociocultural para o choro no início do século XX no que tange ao compartilhamento de uma tradição musical, assim como o seu desenvolvimento. O período corresponde ao aprendizado de Canhoto, onde o músico adquire conhecimento relativo à ordem sonora (estilo, função) do cavaco-centro bem como uma 'bagagem musical' relacionada ao gênero. Acreditamos que seu o estilo começa a configurar-se a partir do momento em que estes elementos, oriundos de seu aprendizado e vivência musical, serão assimilados, interpretados e manifestos em sua prática. A seguir aprofundaremos sobre os processos transmissão musicais no período de aprendizado do músico.

\section{Processos de transmissão musical no Choro}

Sobre os aspectos de aprendizado e transmissão musical no choro, começaremos ponderando as colocações de Aragão (2011) em relação ambiente musical do choro na virada do século XIX e XX através de seu objeto de estudo, o livro O Choro - um dos principais relatos feitos no período. O autor inicia o quarto capítulo de sua tese fazendo uma revisão de trabalhos anteriores que se ocuparam em discutir a questão da transmissão musical.

RIBEIRO, J. F. A construção estilística do cavaquinho e os processos de transmissão musical no choro: a relação Galdino-Álvares-Canhoto. Música Popular em Revista, Campinas, ano 6, v. 1, p. 31-55, jan.-jul. 
Em estudo sobre a transmissão escrita e não escrita, o musicólogo norteamericano Leo Treitler (1992) conclui que a dicotomia entre os dois processos não é sustentável na prática já que, isoladamente, os dois teriam elementos, aspectos questionáveis. O reducionismo de vários aspectos do fazer musical a um objeto concreto (partitura) e a transmissão de uma práxis musical a partir da memória, tendo como principal fonte a performance, seriam alguns destes aspectos.

O etnomusicólogo Bruno Nettl (1983) referencia suas percepções em estudos anteriores como os de Charles Seeger e Curt Sachs, produzidos na década de 1950. Segundo Aragão, Sachs acreditava que a transmissão cultural de um modo geral teria que passar essencialmente por quatro instâncias: oral, escrita, impressa e gravada. As quatro estariam presentes em todas as culturas a partir da segunda metade do século $X X$, sempre mantendo uma relação de interdependência entre si. Aragão também observa que para Nettl, em paralelo à ideia de transmissão musical associada a "peças" musicais fechadas (polcas, valsas, etc.) há um vocabulário de partes menores que o autor denomina de "unidades" (motivos melódicos e rítmicos, acordes, progressões harmônicas, cadências). Ao constatar a presença destas "unidades" em várias obras de um gênero, poderíamos identificar uma linguagem especifica (em nosso caso a ordem sonora) e, assim, estudar o processo de transmissão observando a capacidade do repertório em manter e recombinar esses elementos em uma nova peça musical (ARAGÃO, 2011, p.202-203).

No contexto do choro, observamos uma integração dos processos de transmissão ao longo dos anos, cada um tendo importância em aspectos específicos do conhecimento musical (ensino de instrumentos, conhecimento sobre a cultura do choro, melodias, dentre outros). Para os instrumentos de acompanhamento (violão e cavaquinho) as principais formas de transmissão nesse período eram baseadas na tradição oral (relação professor-aluno) e na observação direta de performances nas rodas de choro.

[...] parece ter sido senso comum entre os chorões da segunda metade do século XX que o choro se aprende prioritariamente através da observação direta e da tradição oral - e mesmo quando o aprendizado se dava através da partitura, esta deveria ser apenas um suporte para a memorização da estrutura básica da música, a ser "completado" por outros aspectos não escritos como "colorido", "improvisação" etc. Desta forma, o "bom chorão" 
prescindiria do registro escrito, pelo menos em seu lugar de práxis, a roda do choro. (ARAGÃO, 2011, p.203)

O autor também comenta que fatores como o não domínio da leitura musical por grande parte dos músicos ligados ao acompanhamento e a impossibilidade de grafar certos aspectos do acompanhamento rítmico-harmônico contribuíram para a disseminação dessas formas de transmissão que, ao longo dos anos, ganharam mais possibilidades. O uso de cifras ou outras formas de notação referente a aspectos interpretativos era quase que inexistente no início do século $\mathrm{XX}$, só tendo surgido décadas depois através de um sistema de cifragem diferente do atual $^{12}$. Posteriormente, as gravações assumiriam a função de registro das performances e transmissão desse material sonoro. A mesma importância deve ser dada ao registro escrito que contribuiu para a manutenção de aspectos como forma e melodia, além de uma característica identitária de instrumentos solistas e, principalmente, dos violões no contexto do choro: os contrapontos. Essa marca estilística tornou-se tão importante para o gênero que hoje, algumas dessas 'frases' são consideradas "obrigações".

Portanto, na virada do século XIX para o XX, elementos como melodia e forma eram resguardados pela partitura, esta sendo fonte primária para os que sabiam ler música (principalmente solistas). Já elementos do acompanhamento rítmico-harmônico, como as "levadas" e fórmulas harmônicas ${ }^{13}$, eram transmitidos através da oralidade. A troca dessas informações acontecia através de interações sociais como a roda de choro.

Alguns músicos mais experientes, que tinham uma compreensão geral das práticas musicais comuns ao gênero, costumavam exercer também uma função didática, transmitindo seus conhecimentos a músicos iniciantes. Em depoimento, Canhoto descreve seu aprendizado quando criança como sendo pautado em posições (desenhos de acordes) que lhes foram transmitidos. Nesse sentido o verbete de Gonçalves Pinto (1936) sobre o flautista Videira é ilustrativo:

\footnotetext{
12 Referiam-se aos acordes de acordo com sua função dentro da progressão harmônica (ex.: “ $1^{\mathrm{a}}$ do tom", " $2^{\mathrm{a}}$ do tom", para tônica e dominante), sendo prática comum nesse período o aprendizado de instrumentos através dos "tons" e das "posições", como se referiam os músicos mais antigos.

13 São progressões de acordes encontradas nas harmonizações dos samba e choros que, de tão recorrentes, foram integradas aos gêneros no âmbito composicional e prático. Ver Almada (2009).

RIBEIRO, J. F. A construção estilística do cavaquinho e os processos de transmissão musical no choro: a relação Galdino-Álvares-Canhoto. Música Popular em Revista, Campinas, ano 6, v. 1, p. 31-55, jan.-jul 
[...] Daquele dia em diante, comecei a procurar Videira, não só em sua casa como em uma charutaria na rua do Ouvidor, onde ele trabalhava como cigarreiro. Andando sempre com ele principiei a tocar violão e cavaquinho, pois ele os conhecia regularmente, e tornando-me desta forma um violão e cavaquinho respeitado na roda dos tocadores batutas (...) tornando-me um bamba nos dois instrumentos de cordas de que fiz uso por muitos anos (GONÇALVES PINTO, 1936, p.32)

Segundo o autor, o flautista tinha conhecimento dos vários aspectos musicais do choro e mesmo sem ler partituras detinha tal conhecimento, devido a prática intensa daquele vocabulário (GONÇALVES PINTO, 1936, p.29). A partir da década de 1950, ao processo de transmissão da ordem sonora referente aos instrumentos de acompanhamento será agregado o processo aural de escuta crítica das gravações, conforme previsto por Sachs em seus estudos. Vale ressaltar que, mesmo com uma possibilidade "mais acessível" (no caso a escuta das gravações), a roda de choro e o contato com músicos tarimbados, ainda hoje, são essenciais na formação do músico nesse contexto. Exemplo disso é a Escola Portátil de Música (EPM), criada em 2000 por músicos de choro que sentiam a necessidade de passar adiante seus conhecimentos sobre o gênero da mesma forma que aprenderam em juventude: através da roda de choro. Iniciou suas atividades com cerca de 50 alunos e tornou-se umas das referências de ensino do choro no Rio de Janeiro, alcançando atualmente cerca 1000 alunos divididos em dois núcleos: Urca (na UniRio) e Casa do Choro.

Luciana Rabello, uma das idealizadoras da escola e apontada como a grande herdeira da escola de Canhoto, narra em entrevista um pouco do seu processo de aprendizado que gravitava entre a prática nas rodas, audição de gravações e a frequência às aulas de violão com o irmão, o violonista Raphael Rabello.

Em 1975, conhecemos o conjunto recém-formado, o Galo Preto. Raphael tinha 12 anos e eu 14. Ficamos amigos e começamos a frequentar as rodas de choro da casa do Afonso Machado -- bandolinista e líder do grupo. Eu ia tocando violão, não tocava cavaquinho ainda. Raphael conheceu o Déo Rian, bandolim do Época de Ouro, que ficou impressionado com ele e mandou que ele fosse ser aluno do Meira, o grande mestre do violão que tocou no Regional do Canhoto e foi mestre do Baden Powell. Além das aulas do Meira, eu e meu irmão passávamos horas tocando com os discos de choro, imitando e aprendendo com as gravações dos mestres, sobretudo do Regional do Canhoto e do Jacob do Bandolim. (RABELLO, 2000, n.p) 
Meira me dava um cavaquinho com cordas de nylon para que o som metálico das cordas de aço não encobrisse o solo de violão. O que ele queria mesmo era que eu mudasse de instrumento. Me ensinou a solar no violão, meu primeiro instrumento, o choro Magoado, do Dilermando Reis. Tocávamos muito e o mestre ia "aparando as arestas", ensinando os caminhos, ampliando os horizontes. As aulas duravam tardes inteiras e tinha muito papo, ouvíamos histórias que nos traziam ensinamentos ainda mais importantes. Começávamos a entender que tocar implicava muito mais do que dominar a técnica de um instrumento (RABELLO, 2009, p.1).

Pelo que se sabe, Meira não era cavaquinista, mas assim como o flautista Videira tinha conhecimentos maiores que levavam Luciana e Raphael a "entender que tocar implicava muito mais do que dominar a técnica de um instrumento". Também destacamos a valorização dos baluartes do choro por parte da "comunidade" (no caso os chorões), sugerindo que o próprio gênero cria suas lideranças, referências para os iniciantes. O depoimento ainda nos fornece detalhes do funcionamento das aulas: à base de muita prática com Meira "aparando as arestas". A expressão certamente refere-se ao fato de o violonista cuidar de alguns pormenores que eventualmente apresentava-se na prática dos aprendizes. Em outro momento, Luciana também ressalta a importância da roda de choro para o seu desenvolvimento musical. $\mathrm{O}$ assunto já foi objeto de um estudo particular ${ }^{14}$ devido à riqueza da discussão e constância do ambiente, em todos os momentos da história do choro, como o principal espaço de aprendizado cultural e interação (musical e social). Ao recordar sua iniciação no choro, a cavaquinista revela a ida às rodas em um bairro do subúrbio do Rio de Janeiro junto com o irmão.

\footnotetext{
Sem ter ainda essa noção sistematizada sobre o gênero, eu e meu irmão Raphael Rabello começamos no choro muito cedo e de forma absolutamente apaixonada. Todas as manhãs de domingo pegávamos o ônibus 498 - Cosme Velho/Penha, que ligava a nossa casa à casa de Joel Nascimento. Iamos rumo às rodas de choro do minúsculo bar Santa Terezinha, na Rua Francisco Enes, bem perto da casa do bandolinista. A roda começava por volta das 10 horas, antes do almoço domingueiro do subúrbio. Encontrávamos ali Joel, Joir (seu irmão violonista), Abel Ferreira, Zé da Velha, índio do Cavaquinho e outros chorões menos conhecidos, como Seu Berredo, Motinha, Petrônio e Caciporé. As rodas sempre acabavam na casa do Abel ou do Joel. Almoçávamos por lá e só voltávamos para casa bem tarde. Esses encontros musicais no bar Santa Terezinha duraram mais ou menos dois anos, tempo produtivo e inesquecível, quando aprendemos muito (RABELLO, 2009, p.1).
}

\footnotetext{
14 Ver Lara Filho et al (2011).

RIBEIRO, J. F. A construção estilística do cavaquinho e os processos de transmissão musical no choro: a relação Galdino-Álvares-Canhoto. Música Popular em Revista, Campinas, ano 6, v. 1, p. 31-55, jan.-jul. 
Em relação ao nosso estudo, sabemos que Canhoto frequentou reuniões musicais na infância, mas seu aprendizado inicial do cavaquinho foi através de um professor. Certamente o contato com a escola antiga se deu através dessas reuniões e de Galdino Barreto. A literatura do período ${ }^{15}$ indica Galdino e Álvares como os principais cavaquinistas na virada do século, fato que os colocaria em evidência para serem observados músicos iniciantes no intuito extrair características, procedimentos utilizados por eles na tentativa de legitimar sua prática ou até mesmo de referenciala.

O período também é marcado por mudanças significativas nos padrões rítmicos do samba que deixam de ser 'maxixados' para se tomarem mais sincopados. Tais mudanças têm forte relação com os padrões de acompanhamento que eram utilizados pelo cavaquinho. Canhoto assim teria seu processo de iniciação e aprendizado musical situado anteriormente às mudanças, quando vigoravam os padrões variantes do tresillo. Porém sua palhetadas apresentam também características diferentes, mais próximas do que seria o "samba batucado". Nesse sentido indagamos se teriam as transformações no samba influenciado a construção estilística de Canhoto.

\section{Transformações rítmicas do samba}

No final da década de 1920 e início da década de 1930 o samba passaria por um processo de mudança, em relação aos padrões rítmicos empregados nos acompanhamentos e também nas composições. As transformações foram estudadas por Carlos Sandroni (2001) que identifica dois ciclos de transformações: "um ciclo curto, que conduziu do estilo antigo ao estilo novo, e um ciclo longo, que conduziu do paradigma do tresillo ao do Estácio [grifo do autor]" (SANDRONI, 2001, p.229). Na música brasileira do final do século XIX e início do século XX são encontrados alguns padrões rítmicos que, de tão recorrentes foram denominados por Mário de Andrade de "sincope característica". Estes padrões rítmicos seriam variações ou subdivisões de um ritmo identificado por musicólogos cubanos na música de seu país, o tresillo, e

\footnotetext{
${ }^{15}$ Ver Gonçalves Pinto (1936), Vagalume (1933) e Barbosa (1933).

RIBEIRO, J. F. A construção estilística do cavaquinho e os processos de transmissão musical no choro: a relação Galdino-Álvares-Canhoto. Música Popular em Revista, Campinas, ano 6, v. 1, p. 31-55, jan.-jul. 
que hoje no Brasil pode ser encontrado na tradição oral das "palmas que acompanham o samba-de-roda baiano, o coco nordestino e o partido-alto carioca" (id. 1999, p.28). Se subdividido, o ritmo assimétrico apresenta-se como um dos ritmos de maior destaque nos acompanhamentos de peças populares do período em questão.

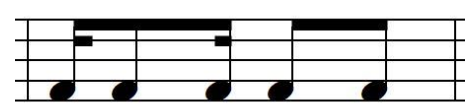

Ex.1 - Sincope característica
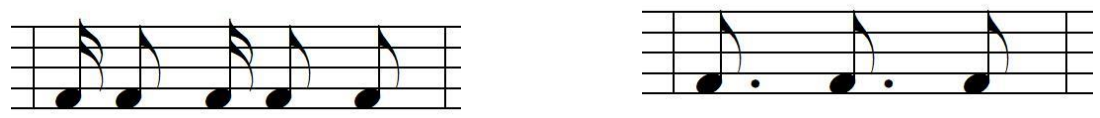

Ex.2 - Tresillo

Para o autor o paradigma do tresillo tem como principal característica a articulação na quarta semicolcheia de um compasso binário distinguindo-se de padrões rítmicos alinhados com a teoria musical clássica que tem sua articulação na quinta semicolcheia. Ao subdividir os grupos temários do tresillo, Sandroni identifica mais duas variações recorrentes na música brasileira: o cinquillo - presente em padrões rítmicos executados pelo cavaquinho em choros do início do século XX (id. 2001, p.29) - e o ritmo de habanera.
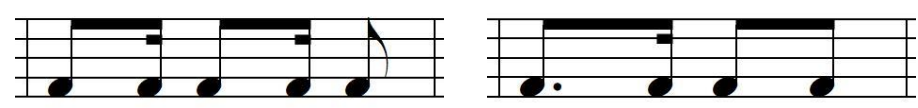

Ex.3 - Cinquillo e Habanera, respectivamente

$\mathrm{O}$ autor ainda comenta que gêneros como lundu, polca-lundu, cateretê, fado, chula, tango, habanera, maxixe e "todas as combinações destes nomes" quando indicados em partituras nacionais do período, tinham o intuito de evocar o caráter sincopado da música tipicamente brasileira. As formas de acompanhamento 
poderiam ser permutáveis, ou seja, utilizadas com o mesmo propósito em mais de um gênero sem haver uma descaracterização deste.

De fato, identificamos nas interpretações de Canhoto tal característica através do uso de uma palhetada-base com eventuais adaptações aos ritmos executados, sempre prezando pela coesão sonora com a formação instrumental. Assim como observado em gravações de Nelson Alves (Mione e Requebros da baianinha - Brunswick 10.065-a e 10.055) essa característica marcante da escola antiga é continuada por Canhoto, porém com algumas inovações rítmicas e melódicas. A análise das gravações revelou que uma das características marcantes do estilo de Canhoto era imprimir em seus acompanhamentos uma rítmica versátil através de movimentos cíclicos que se alternavam entre as regiões grave e o aguda do cavaquinho, construídos sobre ciclos de oito semicolcheias. Este acompanhamento é dinamizado por contrapontos rítmicos (de tercinas $x$ semicolcheias) e duetos (pequenas frases melódicas de duas notas, normalmente em terças, que podem ir ou não em direção ao próximo acorde da progressão harmônica. Sua divisão rítmica varia entre tercinas e sincopes).

O outro paradigma seria o do Estácio, fazendo referência ao bairro do subúrbio carioca onde surgiram tais mudanças por meio de Rubem Barcelos (1904 1927), Ismael Silva (1905 - 1978), Nilton Bastos (1899 - 1931), Bide (1902 - 1975), dentre outros. A sugestão inicial tinha a intenção de melhorar os desfiles carnavalescos, conforme a necessidade declarada por Ismael Silva "de movimentar os braços para frente e para trás durante o desfile" (CABRAL, 2004, p.34). Segundo Cabral, os sambas pioneiros pouco se diferenciavam do maxixe sendo, por esse motivo, mais indicados a dança de salão. Posteriormente, o samba com características 'maxixadas' será rotulado de "samba-maxixe" em oposição ao samba moderno.

Ao assumir que esse grupo de compositores representou uma transformação decisiva para o gênero, Sandroni opta por analisar as gravações do "principal veículo da difusão em larga escala das primeiras composições de Ismael Silva e seus amigos": o cantor Francisco Alves (1898-1952) (SANDRONI, 2001, p.187). A escolha do autor se justifica pela dificuldade em analisar as gravações do período de 1927 a 1933, que compreende a ascensão e o apogeu dos sambas do Estácio. A 
maior parte das gravações desse período foi realizada por orquestras onde não era possível escutar o violão (seu principal parâmetro analítico entre os estilos) e nem elementos rítmicos como cavaquinho, piano ou os instrumentos de percussão. Em busca de um novo parâmetro, o autor identifica na articulação silábica do cantor elementos característicos do estilo novo (SANDRONI, 2001, p.202).

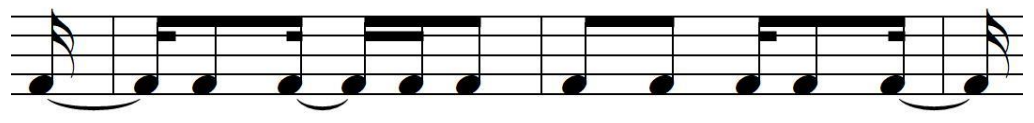

Ex.4 - Paradigma do Estácio

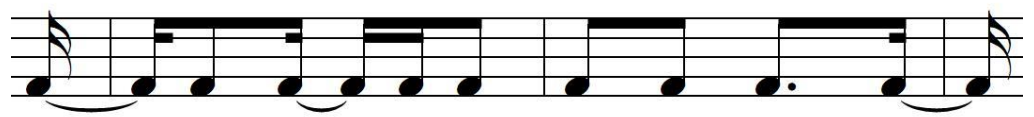

Ex.5 - Paradigma do Estácio (variação)

Na dissertação “Fixando uma gramática: Jayme Florence (Meira) e sua atividade artística nos grupos Voz do Sertão, Regional de Benedito Lacerda e Regional do Canhoto", Iuri Bittar analisou gravações de Meira, companheiro de Canhoto nos regionais, no intuito de identificar elementos estilísticos nos acompanhamentos do violonista. Um desses é a levada "teleco-teco" onde o violão faz referência aos instrumentos de percussão através da execução de células rítmicas, tendo estas relações com o paradigma do Estácio. Para Bittar, a levada parece ser uma "fusão entre elementos tradicionais e 'modernos'" (BITTAR, 2011, p.65), referindo-se aos ritmos presentes nos dois paradigmas. O autor ainda sugere que, pelo fato de Meira estar em intensa atividade no período em que ocorrem as transformações no samba parece instintivo o violonista mesclar ritmos em sua prática.

Márcia Taborda também faz referência a essa levada em sua dissertação intitulada "Dino Sete Cordas: criatividade e revolução nos acompanhamentos da MPB" sobre o terceiro integrante do trio de acompanhamento do Canhoto e Seu Regional. O "violão-tamborim" seria uma batida criada por Dino e utilizada no acompanhamento de sambas daquele momento em diante nas gravações com o кıвнIKU, J. F. A construçao estılıstıca do cavaquinno e os processos de transmıssao musıcaı no choro: a relação Galdino-Álvares-Canhoto. Música Popular em Revista, Campinas, ano 6, v. 1, p. 31-55, jan.-jul. 
Conjunto Regional de Benedito Lacerda (TABORDA, 1995, p.70). Observa-se que na transcrição do "violão-tamborim" apresentada por Taborda o ritmo do paradigma do Estácio não é utilizado na integra, como na levada "teleco-teco" descrita por Bittar.

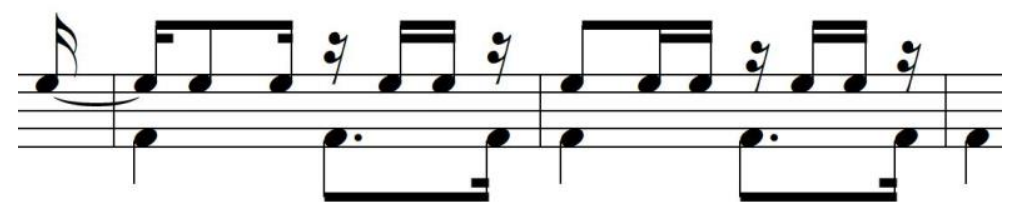

Ex.6 - Levada "teleco-teco"

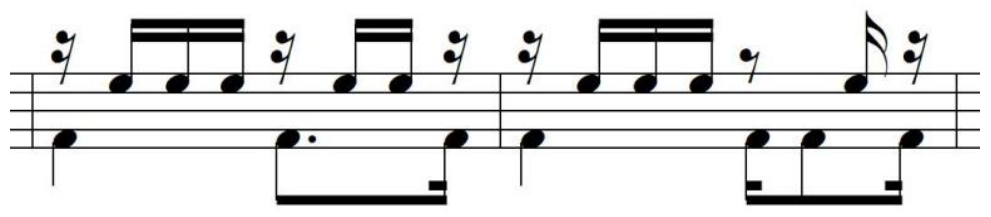

Ex.7 - Violão-tamborim

Ao texto de Bittar, segue um trecho de uma entrevista com Jorginho do Pandeiro $^{16}$ - também companheiro de regional do trio Dino-Meira-Canhoto na década de 1960. A entrevista apresenta detalhes importantes sobre as levadas dos três instrumentistas e, por esse motivo, fazemos questão de citá-la na integra.

Você diz a batucada? Eu vou te contar. O Dino, quando começou a gravar, tinha o Risadinha, que fazia no pandeiro a mesma batida que eu faço. E o Dino começou a fazer essa batida no violão, talvez seja isso que chamam de raspadeira [levada telecoteco] (...) E tem uns sambas antigos que o Dino crava essa batucada, e o Canhoto e o Meira fazem também. Por isso que o conjunto tinha aquela personalidade. Você ouvia de longe e já sabia que era Dino, Canhoto e Meira (Entrevista com Jorginho do Pandeiro apud BITTAR, 2011).

Chamamos atenção para o fato de Jorginho creditar a criação da levada a Dino e sua fixação na música brasileira a da atuação do trio. A partir de uma proposição rítmica de Dino, Meira e Canhoto contribuem para construção de uma sonoridade alusiva à "batida" do pandeirista Risadinha ${ }^{17}$. Em nossas análises podemos observar que Canhoto não utiliza nas palhetadas o motivo rítmico

$16 \mathrm{Na}$ época em que este estudo foi realizado, Jorginho do Pandeiro ainda era vivo. Faleceu em $7 / 07 / 2017$.

${ }^{17}$ Moacyr Machado Gomes (1923-1997).

RIBEIRO, J. F. A construção estilística do cavaquinho e os processos de transmissão musical no choro: a relação Galdino-Álvares-Canhoto. Música Popular em Revista, Campinas, ano 6, v. 1, p. 31-55, jan.-jul. 
completo, que é apresentado nos paradigmas como fazem os violões, por exemplo, mas opta por diluí-lo de modo a integrar à sonoridade geral do trio, como podemos observar no exemplo comparativo entre violão e cavaquinho na música Amanhã eu volto (Columbia 55.343-a) realizadas por Bittar (2011) e pelo autor, respectivamente.

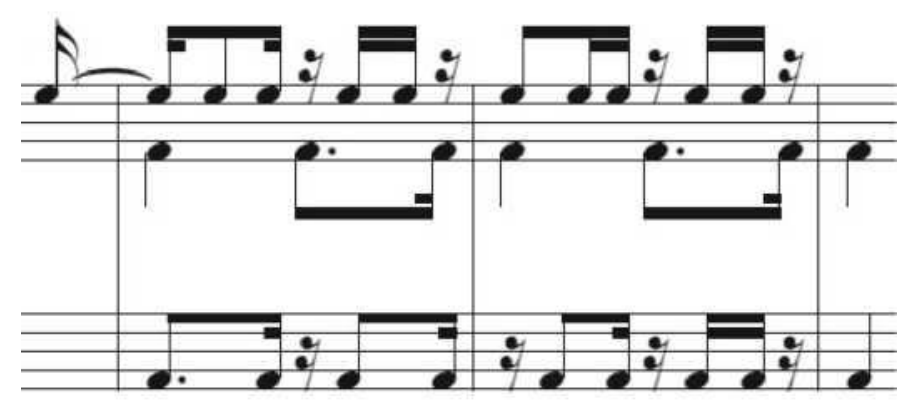

Ex.9 - Levada "teleco-teco" e cavaquinho na música Amanhã eu volto

No pentagrama superior está o padrão rítmico da levada "teleco-teco" executada pelo violão e no inferior a levada do cavaquinho de Canhoto. Observa-se a presença integral do paradigma do Estácio na região aguda da levada do violão e para a célula rítmica padrão nos acompanhamentos de choro de Canhoto, que ocorre no segundo tempo do primeiro compasso e no primeiro tempo do segundo. Nesse caso a palhetada do cavaquinho mescla células rítmicas da síncope característica dos acompanhamentos do cinquillo e células do paradigma do Estácio. Identificamos na gravação de Visite o terreiro (RCA Victor BPL 3060, 1958), de Ary Lobo, em que Canhoto utiliza um ritmo muito parecido com o executado no violão "teleco-teco", sem a parte dos graves.

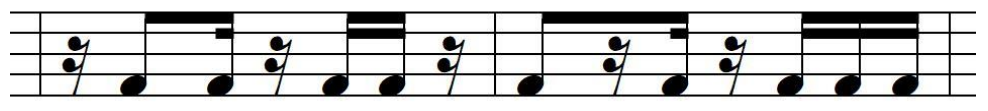

Ex.10 - Palhetada em Visite o terreiro, Ary Lobo. Transcrição do autor

A análise técnica das gravações de Canhoto revelou que o estilo de Canhoto sofre influências de ambos os paradigmas: dos ritmos ligados ao paradigma 
do tresillo bem como das mudanças rítmicas do samba através do Estácio. Como podemos observar, seu período de iniciação e aprendizado musical está relacionado com a escola antiga do cavaquinho (Galdino, Álvares e Alves) e, consequentemente, com ritmos variantes do paradigma do tresillo, como o cinquillo. O músico também vivenciou as mudanças rítmicas do Estácio através da atuação nos regionais: primeiramente com Benedito, Bide e Russo do Pandeiro (envolvidos com as mudanças e moradores do Estácio) e posteriormente com Dino e Meira - este participante de todos os grupos que Canhoto participou.

O ciclo de influências se torna ainda maior quando observamos a quantidade de samba gravados na década de 1930, período em que ocorrem as mudanças. A gradativa participação de músicos ligados ao bairro do Estácio nas gravações também dá margem para a abertura de outro canal de interação entre os paradigmas, fazendo com que as características inovadoras fossem assimiladas pelos músicos acostumados com os padrões da época. Gravações, aliás, que têm grande relevância para consolidação da sonoridade do trio assim como para os estilos individuais dos músicos em questão, além de contribuírem para a divulgação destas práticas por diversas gerações, transformando-os em referência no contexto da música brasileira, principalmente no choro.

\section{O legado de Canhoto}

A transformação de um estilo individual em referência para um gênero popular, certamente, envolve muitas variáveis. Ao analisar a trajetória musical de Canhoto pudemos identificar alguns pontos que podem ter contribuído para sua transformação em um dos pilares centrais do cavaco-centro na música brasileira.

Acima de tudo é indiscutível a qualidade e excelência do músico no ato de acompanhar dentro do contexto do regional. Seu entendimento da funcionalidade de cada instrumento dentro da formação (principalmente em relação ao trio de base ou de acompanhamento) fazia com que o músico priorizasse a utilização de uma palhetada discreta e funcional, de grande integração com os violões. Com Waldiro o cavaquinho abandona sua função quase que exclusiva de manutenção rítmica, RIBEIRO, J. F. A construção estilística do cavaquinho e os processos de transmissão musical no choro: a relação Galdino-Álvares-Canhoto. Música Popular em Revista, Campinas, ano 6, v. 1, p. 31-55, jan.-jul. 
observada nos relatos da virada dos séculos XIX e XX e nas primeiras gravações dos ternos de choro, e passa a ter maiores possibilidades de interação com os outros instrumentos da formação através de dinâmicas, contratempos e intervenções melódicas. Seu modo de conduzir ritmicamente o acompanhamento deu um sotaque único ao seu estilo, transformando-se em marca estilística e peça chave para sua identificação nas inúmeras gravações onde não há ficha técnica disponível.

A visibilidade e difusão de sua prática proporcionadas pelas gravações também são relevantes no processo, pelo fato destas terem se transformado ao longo dos anos em um importante meio de contato entre as performances de chorões consagrados e músicos iniciantes no choro. Canhoto acompanhou por mais de quarenta anos grandes artistas nacionais, cujas canções passaram a fazer parte do repertório clássico da música popular.

Também chama a atenção a desenvoltura com que acompanhava uma grande diversidade de ritmos, alguns onde a presença de um cavaquinho seria improvável na época. O levantamento fonográfico mostra que dois dos maiores sucessos de venda do Regional do Canhoto foram a música norte-americana Jambalaya (RCA Victor 80-1161-a, 1953) e a portuguesa Corridinho (RCA Victor 801233-b, 1954). Ainda figuram no repertório gravado pelo músico, choros, baiões, polcas, maxixes, valsas, batucadas, toadas, emboladas, marchas, samba-canção, jongo, coco, rumba, mazurca, foxtrote, rancheira, cena africana, fandango, entre outros (SANTOS et al, 1982). Certamente muitas destas designações de gêneros são referentes ao período histórico, não sendo ideal compará-las às definições que temos na atualidade. Todavia, podemos considerar que as composições podiam ter sua designação de acordo com o prestígio do gênero frente ao crescente mercado de discos e partituras ou, até mesmo, com a intenção do compositor em torná-las diferente das demais.

Apesar de não ter exercido atividades didáticas, deixou suas maiores lições registradas na grande quantidade de discos gravados ao longo da carreira. A versatilidade e competência de Canhoto na realização dos trabalhos o fizeram imprescindível para o cavaquinho brasileiro. 


\section{Considerações}

Procurei demonstrar, neste artigo, a relação entre a construção estilística do cavaquinho-centro de Canhoto, a prática de cavaquinistas pioneiros do choro (Galdino Barreto, Mário Álvares e Nelson Alves) e o contexto histórico referente ao período de aprendizado musical do músico.

Identificamos que o estilo de palhetada do músico mesclava elementos rítmicos ligados a padrões de acompanhamento do samba anteriores e posteriores às transformações sofridas na década de 1930. Através da relação "professor-aluno" e da observação direta de músicos nascidos no século XIX, assim como o contato com outros músicos oriundos do Estácio em seu processo de profissionalização, Canhoto tem acesso a elementos que serão ressignificados em um novo estilo.

A audição e análise das gravações, juntamente com entrevistas de outros cavaquinistas, nos sugerem que Canhoto prezava o ato de acompanhar os músicos, no sentido de dar suporte a seus companheiros, complementando a sonoridade da formação, daí a atuação em todas as "frentes" do conjunto. Talvez o fato de interagir mais com as proposições rítmicas e harmônicas dos companheiros contribuísse para a utilização de palhetadas que não representem a execução integral de determinado gênero, como demonstrado nas transcrições rítmicas dos violões, mas que também fossem importantes para a coesão sonora do grupo. Acima de tudo, Canhoto compreendia a polifonia do regional de maneira a adaptar-se a qualquer gênero que fosse executado.

\section{Referências bibliográficas}

ALMADA, Carlos. Harmonia Funcional. Campinas, SP: Editora da Unicamp, 2009.

ARAGÃO, Pedro de Moura. O Baú do Animal: Alexandre Gonçalves Pinto e o Choro. 2011. Tese (Doutorado em Música) - UNIRIO, Rio de Janeiro, 2011.

BECKER, José Paulo T. O acompanhamento do violão de seis cordas no choro a partir de sua visão no conjunto Época de Ouro. 1996. Dissertação (Mestrado em Música) - Escola de Música, Universidade Federal do Rio de Janeiro, Rio de Janeiro, 1996. 
BITTAR, Iuri Lana. Fixando uma gramática: Jayme Florence (Meira) e sua atividade artística nos grupos Voz do Sertão, Regional de Benedito Lacerda e Regional do Canhoto. 2011. Dissertação (Mestrado em Música) - Programa de Pós-graduação em Música, Universidade Federal do Estado do Rio de Janeiro, Rio de Janeiro, 2011.

BLACKING, John. How musical is man? Seatle: University of Washinghton Press, 1973.

BLOMBERG, Carla. Histórias da Música no Brasil e Musicologia: uma leitura preliminar. Projeto História, n.43, dezembro, 2011, p.415-444.

CÂNDIDO, Gustavo. Mário Álvares Conceição, RJ 1876 - RJ 10/01/1909. Acervo Digital Mário Álvares. Disponível em: < http:/ / www.marioalvares.com.br/p/sobreo-musico.html >. Acesso em 23 fev. 2019.

CÂNDIDO E SARMENTO, Luciano. Altamiro Carrilho: Flautista e Mestre do Choro. 2005. Dissertação (mestrado) - Universidade Federal da Bahia (UFBA), Escola de Música, Salvador, 2005.

CÔRTES, Almir B. O estilo interpretativo de Jacob do Bandolim. 2006. Dissertação (mestrado) - Universidade Estadual de Campinas (UNICAMP), Instituto de Artes, Campinas, 2006.

FERNANDES, Antônio Barroso (org.). Pixinguinha, Donga, João da Baiana: as vozes desassombradas do museu. Rio de Janeiro, Museu da Imagem e do Som, 1970.

GONÇALVES PINTO, Alexandre. O choro: reminiscências dos chorões antigos. Typ. Glória, fac-símile, 1936. Rio de Janeiro, FUNARTE, 1978.

LARA FILHO, Ivaldo Gadelha; SILVA, Gabriela Tunes da; FREIRE, Ricardo Dourado. Análise do contexto da Roda de Choro com base no conceito de ordem musical de John Blacking. Per Musi, Belo Horizonte, n.23, 2011, p.148-161. Disponivel em: <http://www.scielo.br/pdf/pm/n23/n23a16.pdf> Acesso em: 18 out. 2018.

NELSON ALVES. Instituto Moreira Salles: Pixinguinha 120 anos, 2019. Disponível em: <https://pixinguinha.com.br/perfil/nelson-alves/>. Acesso em 23 de fev. 2019.

PELLEGRINI, Remo Tarazona. Análise dos acompanhamentos de Dino 7 cordas em samba e choro. 2005. Dissertação (mestrado) - Universidade Estadual de Campinas (UNICAMP), Instituto de Artes, 2005.

RABELLO, Luciana. Entrevista concedida a Daniela Thompson sobre a Acari Records para a revista norte-americana Brazzil, 2000. Disponível em:

<http:// daniellathompson.com/Texts/Depoimentos/Luciana_Rabello.htm>. Acesso em: 18 out. 2018.

RIBEIRO, J. F. A construção estilística do cavaquinho e os processos de transmissão musical no choro: a relação Galdino-Álvares-Canhoto. Música Popular em Revista, Campinas, ano 6, v. 1, p. 31-55, jan.-jul. 
A Escola Portátil de Música. Ensaio elaborado especialmente para o projeto Músicos do Brasil: Uma Enciclopédia, patrocinado pela Petrobras através da Lei Rouanet, 2009.

Fevereiro de 2014.

. Entrevista concedida para dissertação de mestrado do Autor em

RIBEIRO, Jamerson Farias. Por uma escrita idiomática de ritmos para o cavaquinho brasileiro. In: CONGRESSO NACIONAL DA ASSOCIAÇÃO BRASILEIRA DE EDUCAÇÃO MUSICAL, XXIII, 2017, Manaus. Anais... Manaus: 2017.

RIBEIRO, Jamerson Farias. O cavaco rítmico-harmônico na música de Waldiro Frederico Tramontano (Canhoto): a construção estilística de um "cavaco-centro" no choro. 2014. Dissertação (Mestrado em Música) - Universidade Federal do Rio de Janeiro, Rio de Janeiro, 2014.

SANDRONI, Carlos. Feitiço decente: transformações do samba no Rio de Janeiro, 1917-33. Rio de Janeiro: Ed. Jorge Zahar/UFRJ, 2001.

SANTOS, Alcino et al. Discografia Brasileira 78rpm. 1902-1964, vols. I e II. Rio de Janeiro: Funarte, 1982.

TABORDA, Márcia. Dino Sete Cordas: Criatividade e revolução nos acompanhamentos da MPB. 1995. Dissertação (Mestrado). Universidade Federal do Rio de Janeiro, 1995. 